\title{
Research on the Promotion of New Energy Vehicles Based on Multi-Source Heterogeneous Data
}

\section{Bing Sun}

Harbin Engineering University

Zhuofang Ju ( $\boldsymbol{\nabla}_{\text {jzf@hrbeu.edu.cn ) }}$

Harbin Engineering University https://orcid.org/0000-0002-1985-0799

\section{Research Article}

Keywords: New energy vehicle, SNA, COVID-19, LDA topic model

Posted Date: January 14th, 2022

DOI: https://doi.org/10.21203/rs.3.rs-1185117/v1

License: 우 (i) This work is licensed under a Creative Commons Attribution 4.0 International License. Read Full License 


\section{Abstract}

Under the background of green development, new energy vehicles(NEVs), as an important strategic emerging industry, play a crucial role in energy conservation and emission reduction. In the post-epidemic era, steadily promoting the promotion of NEVs will be a hot topic. Based on heterogeneous source data, combined with the Latent Dirichlet Allocation (LDA) topic model, Social Network Analysis (SNA), and econometric methods, this paper explores whether individual purchase decisions and company-level cooperative research and development will promote the promotion of new energy vehicles. The results show that whether BEV, HEV, or PHEV, users are more concerned about space dimension, power performance, and design style; Patent collaboration network analysis indicates that NEV enterprises are establishing close partnerships, which will urge the promotion of NEVs; For BEV and HEV models, new energy vehicle companies will invest more patents and R\&D investment will better expedite the advancement of NEVs.

\section{Introduction}

With the development of automobile technology and the highlight of energy problems, countries are paying attention to the development of new energy vehicles. In China, the automobile industry plays an important role in the national economy. However, the rapid development of traditional automobiles inevitably brings about a series of ecological environmental problems such as energy consumption and environmental pollution.[1]Development of new energy vehicles has become the strategic choice of coupling economic, social, and ecological objectives. NEVs are defined as vehicles using unconventional fuel power sources or new power devices, and we focus on battery electric vehicles (BEVs), hybrid electric vehicles (HEVs), and plug-in hybrid electric vehicles (PHEVs) in this paper. As an essential pillar industry, the energy sector is highly sensitive to the external impact of COVID-19(Zhang et al. 2021) The NEV industry has been further hit by the apparent lack of consumer consumption capacity since the COVID-19 outbreak in early 2020 (Li et al. 2021 ). Under the impact of COVID-19, stabilizing the automobile industry and other major consumer consumption has become a top priority for the Chinese government. Both automobile manufacturers and individual consumers are vital participants in promoting new energy vehicles. This paper aims to explore how personal purchase decisions and enterprise technology research and development promote the promotion of NEVs based on multi-source heterogeneous data.

Based on planner behavior theory, Liu et al. (2020) constructed a framework of influencing factors for electric vehicle adoption, taking consumer experience as the antecedent of adoption intention. Wang and Dong (2016) pointed out that subjective norms, perceived ease of use and relative usefulness significantly influenced purchase intentions of new energy vehicles. We have reasons to believe that online comments will affect users' purchase decisions on new energy vehicles, accelerating the promotion of NEVs. While existing research only studies the influence of NEV's policy on promoting NEVs. For example, (Li et al. 2021) used Latent Dirichlet Allocation(LDA) topic model to analyze the policy document of new energy vehicles and its impact on the promotion of new energy vehicles in various cities. Previous studies explored NEV market promotion policy from the aspects of demand-side and supply-side. Purchase subsidy, tax reduction and priority right from demand-side and infrastructure, financial support and regulatory improvement from supply-side(Xiong and Wang 2020).

Based on technology diffusion theory, through extensive technical cooperation, new energy vehicle enterprises can reduce high technology research and development(R\&D) costs, improve technological innovation ability and competitive advantage(Qi Dong et al. 2017). For example, BAIC New Energy has worked together with BAIC Foton, aiming at problems such as short battery life and breaking through the cryogenic technical bottleneck of new energy vehicles(Cheng et al. 2021).

This paper conducts analysis based on multi-source heterogeneous data. Firstly, this paper uses LDA model to analyze online review data of new energy vehicles and study how consumer decisions boost the promotion of new energy vehicles. Secondly, this paper uses social network analysis and econometric model to analyze the R\&D patent cooperation of new energy vehicle companies and explore how the company-level cooperation model accelerates the promotion of new energy vehicles. The rest of this article is organized as follows. Section 2 reviews the relevant literature. Section 3 illustrates the data, variables, and models. In section 4, the research results are analyzed. Section 5 is the results discussion. Section 6 is the conclusion, limitation and future research direction.

\section{Literature Review}

2.1 Individual purchasing decisions facilitate the promotion of NEVs

Based on planner behavior theory, experience may lead to changes in perceived behavioral control and affect willingness and behavior, thus consumers' purchase decision is conducive to the promotion of NEVs(Xiong et al. 2016). Understanding and intervening in these consumer decisions may be critical to accepting electric vehicles (Huang et al. 2021). (He et al. 2012) pointed out that products with good performance will increase consumers' purchase intention. Based on the data marked in the previous phase, Wang et al. (2016)used the idea of migration to get the emotional polarity of the review data of new energy vehicles and made a classification model, providing a method for manufacturers to quickly grasp the emotional tendency. Fang (2010) analyzed the survey data of sales staff with NEVs' sales experiences and found potential factors, including purchasing behavior of people around, energy consumption cost, brand impact, exterior and interior. These factors have impact on NEVs purchasing decision. Technological performance is the most relevant among the factors influencing the diffusion of NEVs. Previous studies have revealed that Asian consumers are equally focused on the technical and functional features of electric vehicles, the appearance of the vehicles also matters a lot to them(Goel et al. 2021). In addition, performance considerations of new energy vehicles also play an important role in the purchase decision process (Adamson 2005). With that in mind, we put more emphasis on the research of individual purchasing decisions to promote NEV promotion.

\subsection{NEV text mining and analysis}

To understand latent information of new energy vehicles online review more efficiently and quickly, this study uses text mining method to identify and analyze online review information. 
Text mining refers to analyzing and predicting texts through statistical modelling and other means and obtaining information in the text. The most commonly used text mining methods include cluster analysis and sentiment analysis(Ding et al. 2021). It helps to mine the comment text for more important information. At present, China's research in the field of new energy vehicles only stays in the interpretation of policy documents. Therefore, this paper uses the LDA classification model to analyze the promotion status of NEVs from the perspective of users' purchasing decisions.

\subsection{Company level facilitate the promotion of NEVs}

Based on technology diffusion theory, as a typical emerging industry, technological factors present one of the most significant challenges to the NEV promotion(Liu et al. 2018). New energy vehicles adopt emerging technologies, and the core of industrial competitiveness lies in technological innovation (Ruan et al. 2017). In addition to R\&D spending, another direct production of technological innovation is patent, which reflects the latest technological advances. Patent information is valuable for analyzing the investigated enterprise, and the space for technological progress can be found from the obtained patent information, so as to accelerate the promotion of NEVs(Sun et al. 2018). One efficient way of analyzing NEV promotion from the company level is by discovering knowledge from existing technology data sources, promoting new technological innovation, and putting them on the market as soon as possible (Hewu et al. 2014『Xie and Tian 2015).

These studies mainly focus on the direct analysis of patent data, social network analysis is mainly used to study the evolution of the new energy vehicle industry. Few scholars conduct research based on patent cooperation of new energy vehicle companies. By establishing patent cooperation network analysis between companies, the potential of China's new energy vehicle technology innovation is revealed.

\section{Method}

\subsection{Latent Dirichlet allocation model}

The basic assumption of LDA model is that each document is composed of a mixture of topics with a certain probability, and each topic is also composed of a mixture of features with a certain probability, thus forming a three-layer Bayesian probability model of "document-topic-feature". The core formula is as follow:

$P(w \mid d)=P(w \mid t) * P(t \mid d)$

(1)

Based on the NEV evaluation text from the Pacific Automobile network囚we use the Jieba package to segment words by Python 3.8 software. We cleaned them up for useless words such as "of," "is," and punctuation by adding the stop words list. In the LDA model, perplexity can be understood as the uncertainty degree that the model trained for a document that belongs to a certain topic. The lower the degree of confusion, the better the clustering effect of the model. Afterward, the whole data is divided into 7 topics by the perplexity method, and the top 10 keywords are extracted from each topic.

\subsection{Social Network analysis}

\subsubsection{Methodology}

SNA is an interdisciplinary academic method used in social psychology, sociology, statistics, and graph theory (Sun et al. 2018). Moreover, SNA is extensively used to examine the trend of patent collaboration networks (Moussa and Varsakelis 2017), illustrating collaboration networks between invention institutions and applicant organizations. Also, many scholars used SNA to analyze citation networks(Chang et al. 2009).

Gephi is an easy to access, powerful network analysis software, it is based on the Java virtual machine open-source network analysis software. It is mainly used to visualize various networks, complex systems, and layered graphs. Summarizing the above, in this paper, we employed an SNA method and used Gephi to explore the patent collaboration network for new energy vehicles.

\subsubsection{Data sources}

The patent data used in this paper come from the patent retrieval and analysis system built by the State Intellectual Property Office of China (SIPO). The original applicant was chosen to obtain the patent relationship for different companies. The authors manually cut and downloaded the data from 2016 to 2020 to ensure data integrity.

\subsection{Econometric model}

\subsubsection{Dependent variable}

Sales refer to the annual sales of NEVs of the companies during the study period. The data comes from Wind Economic Database (WIND). Sales of new energy vehicles can clearly show the promotion effect of the new energy vehicle market. As consumers' decision to buy traditional or new energy vehicles affects marketing, it is important to ensure the success of marketing.(Liu et al. 2018).

\subsubsection{Independent variable}


Patent refers to the technological progress of the enterprise during the research period, expressed by the number of patent applications for new energy vehicles. (including invention patents, utility model patents, design patents). We used the keyword= (new energy vehicles OR electric vehicles OR Hybrid electric vehicles OR plug-in hybrid electric vehicles) from the National Intellectual Property Administration website to collect the NEV patents. Sun et al. (2018) found that the patent pool of new energy vehicles is established to maximize knowledge spillover and technology diffusion.

Rd refers to the firm's R\&D intensity and uses R\&D investment in the company's current year as our control variable.

\subsubsection{Control variables}

Fix refers to fixed assets investment. Innovation subsidies on new energy vehicles firms and fixed assets investment will promote technological progress(Wang et al. 2021).

Cha refers to an annual number of charging piles during the study period. A sufficient number of charging piles is conducive to the promotion of new energy vehicles.(Egnér and Trosvik 2018). In addition, the more convenient the charging device, the more willing consumers are to accept it. (Ma et al. 2019).

According to the availability of data, this paper collects data from 26 representative listed companies of new energy vehicles from 2016 to 2020 to construct a regression model. This paper uses LDA topic model analysis of the data extracted from The Pacific Automobile network and then uses social network analysis of the involved companies. In the process, we found that some companies didn't have enough data. This article will remove samples of companies that lack too much data. We assume that all variables can promote the sales of new energy vehicles. The specific variables definition is shown in Table 1.

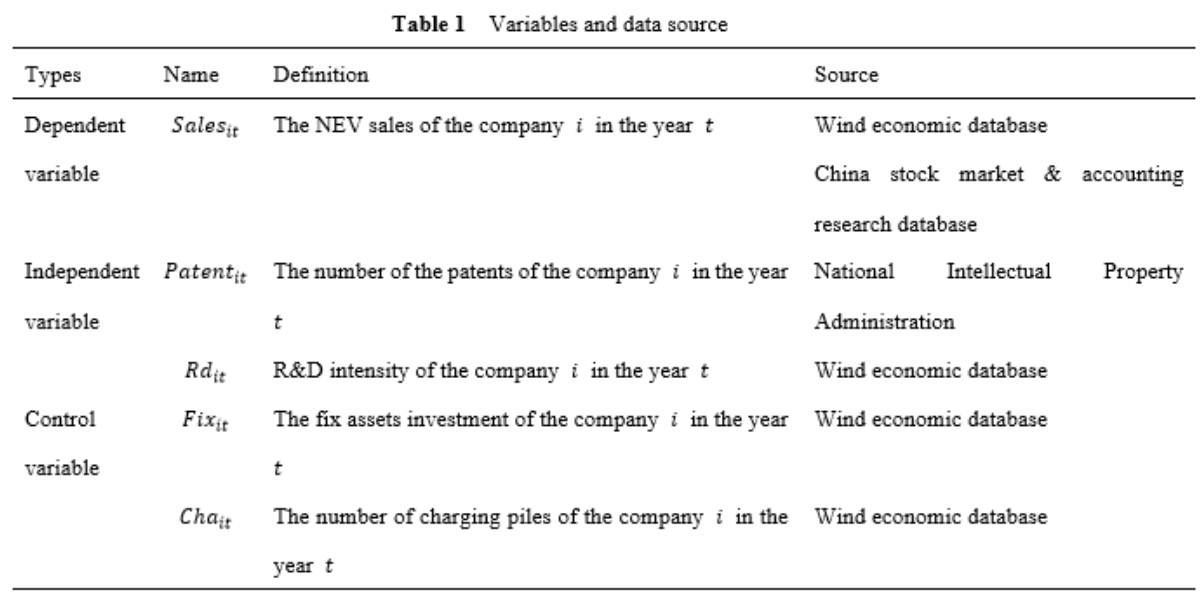

Formula (2) uses panel data model to study the relationship between total sales of new energy

vehicles and sales of different models. In the research process, the total sample data were firstly

regression, and then $\mathrm{BEV}, \mathrm{HEV}$ and $\mathrm{PHEV}$ samples were grouped regression according to different NEV

models. The influence mechanism of each group of samples was tested separately. $\alpha$ is the intercept

term. $\beta_{1}, \beta_{2}$ is the coefficient of the ihdependent variable. $\gamma_{1}, \gamma_{2}$ is the coefficient of the control

variable. $\varepsilon_{i t}$ is an error disturbance term.

lnSales $_{i t}=\alpha+\beta_{1}$ Patent $_{i t}+\beta_{2} \ln R d_{i t}+\gamma_{1} \ln F i x_{i t}+\gamma_{2} \ln C h a_{i t}+\varepsilon_{i t}$

(2)

\section{Result And Discussion}

\subsection{The result of the latent Dirichlet allocation model}

Table 2 shows the list of hot words for each topic and the probability distribution of the hot words. Divide the entire data into 7 topics, and extract the top 10 keywords from each topic.

In topic 1, keywords such as "space", "back row" and "comfortable" reflect the user experience of new energy vehicles in space dimension. It can be seen that users have higher and higher requirements for car space. New energy vehicle enterprises should improve the vehicle space comfort and utilization rate to meet user needs to promote the promotion of new energy vehicles.

In topic 2, keywords such as "appearance", "design" and "modelling" reflect the appearance characteristics of new energy vehicles. It can be seen that online comments on the appearance of new energy vehicles tend to be highly satisfactory. The improvement and enhancement of the appearance design of new energy vehicles will enhance the visual enjoyment of users.

In topic 3, keywords such as "back row," "seat," and "big" reflect the comfort degree of new energy vehicles. It can be seen that users still attach great importance to the comfort of new energy vehicles, and improving the ease of various models will promote the promotion of new energy vehicles. 
In topic 4, keywords such as" configuration", "lunch" and "function" reflect the power performance of new energy vehicles. It can be seen that users have high requirements for power when purchasing new energy vehicles. Therefore, from the technical point of view, improving the dynamic performance of new energy vehicles will promote users to make purchase decisions.

In topic 5, keywords such as "trim", "wrapping" and" Sound insulation" reflect configuration of new energy vehicles. It can be seen that whether the configuration of new energy vehicles is comprehensive will affect users' purchase decisions. Therefore, improving the configuration of new energy vehicles can stimulate the promotion of new energy vehicles.

In topic 6『keywords such as "fuel consumption", "hundreds of kilometers" and "fuel saving" reflect the fuel consumption of new energy vehicles. It can be seen that users still look at the fuel consumption of re-energy vehicles, and users usually choose new energy vehicles or value fuel economy than fuel cars.

In topic 7, keywords such as "design", "center control" and "trim" reflect the design style of new energy vehicles. Automotive system design is an important part of the car body. Improving car body design will bring better visual enjoyment to users and accelerate the promotion of new energy vehicles.

To sum up, the LDA model classifies the text into seven topics: space dimension, appearance characteristics, comfort degree, power performance, configuration, fuel consumption and design style. In the next step, we will calculate the topic probability of different types of new energy vehicles.

Table 2 The top words for different topics

\begin{tabular}{|c|c|c|c|c|c|c|c|}
\hline Topic & Topic 1 & Topic 2 & Topic 3 & Topic 4 & Topic 5 & Topic 6 & Topic 7 \\
\hline \multirow{20}{*}{$\begin{array}{l}\text { Top words } \\
\text { with high } \\
\text { probability }\end{array}$} & Space & \multirow[t]{2}{*}{ Appearance (0.045) } & Space & Super & \multirow[t]{2}{*}{ Configuration (0.067) } & \multirow{2}{*}{$\begin{array}{l}\text { Fuel } \\
\text { consumption } ₫ 0.064 \rrbracket\end{array}$} & Trim \\
\hline & $凶 0.065 \rrbracket$ & & $凶 0.078 \rrbracket$ & $(0.080)$ & & & $(0.038)$ \\
\hline & \multirow[t]{2}{*}{ Household $\llbracket 0.056 \rrbracket$} & Car body & Back row & Vehicle & Well & Perfect & Energy \\
\hline & & $(0.032)$ & $(0.032)$ & $(0.032)$ & $(0.046)$ & $\llbracket 0.032 \rrbracket$ & $\triangle 0.037 \rrbracket$ \\
\hline & Power & Design & Big & Launch & Trim & \multirow{2}{*}{$\begin{array}{l}\text { Approximately } \\
₫ 0.021 \rrbracket\end{array}$} & Design \\
\hline & $\triangle 0.040 \rrbracket$ & $(0.023)$ & $(0.030)$ & $(0.030)$ & $(0.033)$ & & $\triangle 0.031 \rrbracket$ \\
\hline & \multirow{2}{*}{$\begin{array}{l}\text { Enough } \\
\text { space } \llbracket 0.022 \rrbracket\end{array}$} & \multirow[t]{2}{*}{ Good-looking $₫ 0.020 \rrbracket$} & Vehicle & Power & Seat & \multirow{2}{*}{$\begin{array}{l}\text { Hundreds of } \\
\text { kilometers } \\
\text { ख0.020区 }\end{array}$} & Vehicle \\
\hline & & & $(0.025)$ & $(0.027)$ & $(0.032)$ & & $(0.025)$ \\
\hline & Big & Grand & Seat & \multirow{2}{*}{$\begin{array}{l}\text { Configuration } \\
\square 0.026 \rrbracket\end{array}$} & Aspect & \multirow[t]{2}{*}{ High speed $\quad \varangle 0.017 \rrbracket$} & \multirow{2}{*}{$\begin{array}{l}\text { Center } \\
\text { control } 1\end{array}$} \\
\hline & $\bowtie 0.019 \rrbracket$ & $(0.020)$ & $(0.024)$ & & $₫ 0.031 \rrbracket$ & & \\
\hline & Back row & Power & Compare & Drive & Wrapping $₫ 0.030 \rrbracket$ & Fuel saving & Not bad \\
\hline & $凶 0.017 \rrbracket$ & $(0.018)$ & & $(0.024)$ & & $₫ 0.015 \rrbracket$ & $(0.020)$ \\
\hline & \multirow[t]{2}{*}{ Satisfaction $₫ 0.015 \rrbracket$} & Modelling & Super & Radar & Price & \multirow{2}{*}{$\begin{array}{l}\text { Kilometers } \\
₫ 0.015 \rrbracket\end{array}$} & \multirow[t]{2}{*}{ Weakne } \\
\hline & & $(0.017)$ & $(0.017)$ & $(0.021)$ & $\varangle 0.024 \rrbracket$ & & \\
\hline & Seat & Fashion & Problem & Function & \multirow[t]{2}{*}{ workmanship $₫ 0.022 \rrbracket$} & Downtown & Very \\
\hline & $\otimes 0.014 \rrbracket$ & $(0.017)$ & $(0.013)$ & $(0.020)$ & & $\varangle 0.013 \rrbracket$ & $\triangle 0.016 \rrbracket$ \\
\hline & Drive & Line & Front row & Grand & \multirow[t]{2}{*}{ Satisfaction $\llbracket 0.017 \rrbracket$} & \multirow[t]{2}{*}{$\begin{array}{l}\text { Cost performance } \\
(0.013)\end{array}$} & Speed u \\
\hline & $\llbracket 0.014 \rrbracket$ & $(0.015)$ & $(0.012)$ & $₫ 0.016 \rrbracket$ & & & $(0.016)$ \\
\hline & \multirow[t]{2}{*}{ Comfortable $\varangle 0.013 \rrbracket$} & \multirow[t]{2}{*}{ Aggressiveness $₫ 0.015 \rrbracket$} & Appearance & \multirow{2}{*}{$\begin{array}{l}\text { Facial } \\
\text { attractiveness } \\
(0.015)\end{array}$} & \multirow{2}{*}{$\begin{array}{l}\text { Sound } \\
\text { insulation } \varangle 0.016 \rrbracket\end{array}$} & Engine & Style \\
\hline & & & $(0.011)$ & & & $(0.012)$ & $(0.016)$ \\
\hline
\end{tabular}

From the LDA topic model results, we can acquire the probability that different types of new energy vehicles belong to the seven topics. We calculate the topic probability of different types of NEV. As shown in table 3, the sum of each type of NEV probability on the seven topics is 1 . In topic 1 , the probability of BEV, HEV and PHEV was $0.156650817,0.145172706$ and 0.150695731 , respectively. In topic 4, the probability of BEV, HEV and PHEV was $0.1569808,0.1415047$ and 0.1525061 , respectively. In topic 7, the probability of BEV, HEV and PHEV was $0.19157723,0.18748437$ and 0.17895406 , respectively. Whether BEV, HEV or PHEV, users are more concerned about space dimension, power performance and design style. The three vehicle models should enhance the power performance from the technical point, enhance the space utilization rate from the body structure, and improve the design style from the appearance. This can urge the promotion of new energy vehicles.

Table 3 The topic prevalence for different types of new energy vehicle 


\begin{tabular}{|llllllllll|}
\hline vehicle model & \multicolumn{3}{l}{ The topic probability distribution of each vehicle model } & & & & The sum of topics \\
& Topic1 & Topic 2 & Topic 3 & Topic 4 & Topic 5 & Topic 6 & Topic 7 \\
BEV & 0.156650817 & 0.1341561 & 0.1486017 & 0.1569808 & 0.07276582 & 0.1392675 & 0.19157723 & 1 \\
\hline HEV & 0.145172706 & 0.134628 & 0.1227469 & 0.1415047 & 0.13688814 & 0.1315752 & 0.18748437 & 1 \\
\hline PHEV & 0.150695731 & 0.1220672 & 0.1284948 & 0.1525061 & 0.13326798 & 0.1340141 & 0.17895406 & 1 \\
\hline
\end{tabular}

\section{2 the result of the social network analysis}

Considering the technological collaboration, figure 1 shows the network in each period of analysis. In this paper, each patent-filing company is treated as a network node, and the node size and color depth represent the number of other nodes connected to the node. An edge captures hence interactions between two applicants involved promotion of new energy vehicles. These interactions may take place because the technological invention occurred in collaboration.

According to the relevant patent data selected in this paper, patent applications are all enterprises. This figure shows that enterprise contributes a lot to cooperation in the new energy vehicles field, as the dominant part for participating in collaborative patents. With the development of new energy vehicle industry, enterprises are more inclined to convert technological innovation into patents. Enterprises conduct patent research and development cooperation to promote the technological progress of new energy vehicles, urge the promotion of new energy vehicles and occupy market share. The expansion of enterprise networks means the increase of cooperative relations among enterprises, and the accumulation of knowledge inside the network leads to the increase of knowledge and technology spillover among enterprises. In general, this patent collaboration network indicates that NEV enterprises are establishing a close partnership.

\section{3 the result of the econometric model}

According to the result of Section 4.1, 4.2, after analyzing the promotion of NEVs by individual purchase decision and the promotion of NEVs by patent cooperation of NEVs companies. We further explore the promotion of NEVs by the patent and R\&D investment of NEVs companies. As shown in Table 4, the regression coefficient of patent was significant at 0.01 level $(\beta=0.001, P<0.01)$. That is, patents promote the promotion of NEVs. The regression coefficient of R\&D investment was significant at 0.01 level $(\beta=0.348, P<0.01)$. That is, R\&D investment accelerates the promotion of NEVs. In addition to the control variables, the regression coefficient of fixed assets investment was significant at 0.01 level $(\beta=0.328, P<0.01)$. That is, fixed assets investment accelerates the promotion of NEVs.

Table 4 The regression results

\begin{tabular}{ccccccc}
\hline InSales & Coef. & Std.Err. & t-value & $\mathrm{P}>|\mathrm{t}|$ & {$[95 \%$ Conf } & Interval $]$ \\
\hline Patent & $0.001^{* * *}$ & 0.000 & 4.810 & 0.000 & 0.001 & 0.002 \\
$\ln R d$ & $0.348^{* * *}$ & 0.081 & 4.280 & 0.000 & 0.188 & 0.508 \\
$\ln F i x$ & $0.328^{* * *}$ & 0.083 & 3.950 & 0.000 & 0.164 & 0.491 \\
$\operatorname{lnCha}$ & 0.313 & 0.222 & 1.410 & 0.160 & -0.125 & 0.752 \\
Constant & -9.238 & 4.002 & -2.310 & 0.022 & -17.130 & -1.346 \\
\hline
\end{tabular}

$*, * *$, and $* * *$ denote the significance levels of $10 \%, 5 \%$, and $1 \%$, respectively.

According to the previous analysis, NEV is categorized into three types, but the impact mechanism of different types of NEVs on the promotion of NEVs is still unclear. We further explore whether the heterogeneity of the types of NEVs may differ in the promotion of NEVs. As shown in Table 5, it can be seen that the regression coefficient of patent is significant at the level of 0.01 in all three groups. The regression coefficient of R\&D investment is significant at the level of 0.05 in BEV and is significant at the level of 0.01 in HEV. For BEV and HEV models, new energy vehicle companies will invest more patents, and R\&D investment will better expedite the promotion of NEVs.

\begin{tabular}{clll}
\multicolumn{4}{c}{ Table 5 The regression results were grouped according to NEV heterogeneity } \\
\hline & BEV & HEV & PHEV \\
\hline Patent & $0.001^{* *}(2.170)$ & $0.002^{* * *}(3.370)$ & $0.002^{* * *}(3.170)$ \\
$\operatorname{lnRd}$ & $0.311^{* *}(2.510)$ & $0.570^{* *+}(4.470)$ & $0.015(0.090)$ \\
$\ln$ Fix & $0.502^{* * *}(4.09)$ & $0.194(1.450)$ & $0.061(0.350)$ \\
$\ln$ Cha & $0.173(0.54)$ & $.482(1.330)$ & $0.297(0.660)$ \\
Constant & -10.814 & -13.372 & 5.359 \\
\hline
\end{tabular}

Note: The number in parentheses are $t$ statistics.

$\star, \star \star$, and $* \star \star$ denote the significance levels of $10 \%, 5 \%$, and $1 \%$, respectively.

\section{Conclusion}


5.1 conclusion of the results

Based on multi-source heterogeneous data, this paper studies the impact of individual consumption decisions and corporate R\&D cooperation on the promotion of new energy vehicles. Based on reviewing the existing literature, LDA model is used to analyze the evaluation text of new energy vehicle website, and NETLOGO is used to analyze the social network. The patent cooperation between new energy vehicle enterprises is studied. Finally, the econometric method is used to analyze the impact of the company's R\&D investment on promoting new energy vehicles. The main conclusions are as follows:

Q1هThis study uses LDA model to analyze the evaluation text of new energy vehicle websites. Whether BEV, HEV or PHEV, users are more concerned about space dimension, power performance and design style. The three vehicle models should enhance the power performance from the technical point, enhance the space utilization rate from the body structure, and enhance the design style from the appearance. This can urge the promotion of new energy vehicles.

\2囚This study uses Gephi software to conduct social network analysis on patents of new energy vehicle companies. Patent collaboration network analysis indicates that NEV enterprises are establishing close partnerships, which will urge the promotion of new energy vehicles.

\3囚This study further explores the promotion of NEVs by patent and R\&D investment of NEV companies. And then BEV, HEV and PHEV samples were grouped regression according to different NEV models. The influence mechanism of each group of samples was tested separately. For BEV and HEV models, new energy vehicle companies will invest more patents and R\&D investment will better expedite the promotion of NEVs.

\subsection{Theoretical contributions}

This paper makes three main theoretical contributions.

First, most of the previous studies of scholars started from a single data, and most of them started from the perspective of policies (extending subsidies for new energy vehicles, exempting vehicle purchase tax). Based on multi-source heterogeneous data, this paper studies how to accelerate the promotion of new energy vehicles from the perspective of the individual purchase decision and company level. This paper expands the research on the promotion of new energy vehicles.

Second, based on the theory of planner behavior and technology diffusion, this paper puts forward an empirical analysis of how individual purchase decisions and company level promote the promotion of new energy vehicles from the perspective of multi-source heterogeneous data. The research results of this paper extend the boundary between planner behavior theory and technology diffusion theory.

Third, based on the perspective of multi-source heterogeneous data, this paper conducts an empirical study using the LDA model to analyze online review text of new energy vehicles and using social network analysis to analyze patent data. In addition, econometrics is also used to analyze enterprise panel data. This paper provides a new research perspective for promoting new energy vehicles.

\subsection{Managerial and policy implications}

The findings of this study provide clear policy implications for enterprises and policy practitioners.

First, regarding the impact of individual purchasing decisions, users are more concerned with spatial dimension, power and design style. Therefore, HEV, BEV and PHEV three models should improve the power performance from the technology, improve the space utilization rate from the body structure, improve the design style from the appearance, to promote the promotion of new energy vehicles. According to the market demand for new energy vehicle products, enterprises should implement targeted model transformation. New energy vehicle enterprises should use information technology, big data and other ways to change the relationship between enterprises and consumers. Understand the needs of consumers in the new energy vehicle market, start from consumers' purchasing decisions, transform and upgrade new energy vehicle products, improve vehicle performance, and provide consumers with appropriate products.

Secondly, from the perspective of company-level patent cooperation and R\&D investment, enterprises and policy practitioners of new energy vehicles should jointly promote innovative R\&D of new energy vehicles and provide adequate financial support. Enterprises should increase investment in innovative human resources, attract more high-level technical talents in the market and promote patent cooperative research and development by expanding talent introduction channels. In addition, enterprises should expand R\&D cooperation channels with other new energy vehicle companies, promote patent research and development, and accelerate the promotion of new energy vehicles. Policy practitioners should increase investment in the research and development of new energy vehicles and promote innovative research and development of new energy vehicle enterprises.

\subsection{Limitations and future research}

Although this study has well answered the research questions raised in the introduction, there are still some limitations. Our research can be extended in several directions. First of all, we only selected one of the most famous automobile websites in China based on the evaluation text of new energy vehicle websites. It would be interesting to add the evaluation text of other websites. Second, we only analyze the impact of patent cooperation and R\&D investment. Another interesting direction for future research is to consider the overall impact mechanism.

\section{Declarations}

Availability of data and materials Not applicable

\section{Author contribution}


The manuscript was approved by all authors for publication. Bing Sun and Zhuofang Ju conceived and designed the study. Zhuofang Ju performed the experiments and wrote the paper. Bing Sun reviewed and edited the manuscript.

Ethics approval This article does not involve the ethical problem.

Consent to participate Not applicable

Consent for publication Not applicable

Competing interests The authors declare no competing interests.

\section{Funding}

This work was supported by the National Natural Science Foundation of China "MLP-based knowledge-intensive industry leading technology formation mechanism and promotion policy research" [grant number 71774035]; Heilongjiang Province Natural Science Foundation project "research on identification and establishment of knowledge-intensive industry leading technology" [grant number LH2020G005].

\section{References}

1. Adamson, K. A.2005. Calculating the price trajectory of adoption of fuel cell vehicles. International Journal of Hydrogen Energy 30(4): 341-350.

2. Chang, S.B., K.K. Lai and S.M. Chang.2009. Exploring technology diffusion and classification of business methods: Using the patent citation network. Technological Forecasting and Social Change 76(1): 107-117.

3. Cheng, L., Y. Liu, X. Lou, Z. Chen and Y. Yang.2021. Does technology conglomeration promote innovative outcomes of new energy vehicle enterprises? The moderating effect of divisive faultlines. Journal of Cleaner Production 324:120959-126526.

4. Ding, Z., R. Liu and H. Yuan.2021. A text mining-based thematic model for analyzing construction and demolition waste management studies. Environmental Science and Pollution Research: 1-29.

5. Egnér, F. and L. Trosvik.2018. Electric vehicle adoption in Sweden and the impact of local policy instruments. Energy policy 121:584-596.

6. Fang, X. U. G.h. X. U.2010. Impact Factors of Purchase Decision of New Energy Automobile. China population, resources and environment 11.

7. Goel, P., N. Sharma, K. Mathiyazhagan and K. E. K. Vimal.2021. Government is trying but consumers are not buying: A barrier analysis for electric vehicle sales in India. Sustainable Production and Consumption 28:71-90.

8. He, L., W. Chen and G. Conzelmann.2012. Impact of vehicle usage on consumer choice of hybrid electric vehicles. Transportation Research Part D: Transport and Environment 17(3): 208-214.

9. Hewu, W., S. H. I. Hong, C. Ping and O. Minggao.2014. Analysis on the progress of energy saving and new energy vehicle industrialization in China based on a database. Journal of Automotive Safety and Energy 5(03): 1674-8484.

10. Huang, X., Y. Lin, F. Zhou, M. K. Lim and S. Chen.2021. Agent-based modelling for market acceptance of electric vehicles: Evidence from China. Sustainable Production and Consumption 28:206-217.

11. Li, J., J. Jiao, Y. Xu and C. Chen.2021. Impact of the latent topics of policy documents on the promotion of new energy vehicles: empirical evidence from Chinese cities. Sustainable Production and Consumption 28:637-647.

12. Liu, R., Z. Ding, X. Jiang, J. Sun, Y. Jiang and W. Qiang.2020. How does experience impact the adoption willingness of battery electric vehicles? The role of psychological factors. Environmental Science and Pollution Research 27(20): 25230-25247.

13. Liu, Z., H. Hao, X. Cheng and F. Zhao.2018. Critical issues of energy efficient and new energy vehicles development in China. Energy Policy $115: 92-97$.

14. Ma, Y., T. Shi, W. Zhang, Y. Hao, J. Huang and Y. Lin.2019. Comprehensive policy evaluation of NEV development in China, Japan, the United States, and Germany based on the AHP-EW model. Journal of cleaner production 214:389-402.

15. Qi Dong, J., K. J. McCarthy and W. W. M. E. Schoenmakers.2017. How central is too central? Organizing interorganizational collaboration networks for breakthrough innovation. Journal of Product Innovation Management 34(4): 526-542.

16. Ruan, J., P. D. Walker, N. Zhang and J. Wu.2017. An investigation of hybrid energy storage system in multi-speed electric vehicle. Energy 140:291-306.

17. Sun, H., Y. Geng, L. Hu, L. Shi and T. Xu.2018. Measuring China's new energy vehicle patents: A social network analysis approach. Energy 153:685-693.

18. Wang, S., J. ZHang and Y. Li 2016. Sentiment Preddiction for Car Review Based on Active Learning. Journal of Shanxi University 39(1):49-55.

19. Wang, X., Z. Li, R. Shaikh, A. R. Ranjha and L. K. Batala.2021. Do government subsidies promote financial performance? Fresh evidence from China's new energy vehicle industry. Sustainable Production and Consumption 28:142-153.

20. Wang, Z. and X. Dong.2016. Determinants and policy implications of residents' new energy vehicle purchases: The evidence from China. Natural Hazards 82(1): 155-173.

21. Xie, Q. and Z. L. Tian .2015. Text analysis of China's new energy vehicle industry policy, Trans Tech Publ.

22. Xiong, Y. and L. Wang.2020. Policy cognition of potential consumers of new energy vehicles and its sensitivity to purchase willingness. Journal of Cleaner Production 261: 120959-126526.

23. Xiong, Y. Q., M. L. Chen and S. O. Business.2016. Study of the new energy vehicles demand market's cultivated policy orientation: supply side or demand side. China population. Resour Environ 26:129-137. 
24. Zhang, L., H. Li, W.J. Lee and H. Liao.2021. COVID-19 and energy: Influence mechanisms and research methodologies. Sustainable Production and Consumption.

\section{Figures}

Figure 1

Company patent collaboration network map 